\title{
Franz gerstenbrand (1924-2017) the world ambassador of neurosciences in memoriam aeternam
}

Volume 7 Issue 6 - 2017

\author{
Opinion

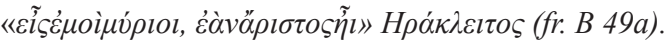 \\ "One is ten thousand to me, if he be the best". Heracletus (fr. B \\ 49a).
}

The Neurological sciences are deprived of the eminent professor of Neurology and honorary doctor of many universities Franz Gerstenbrand, who passed away peacefully on the 30th of June, 2017.

The late Professor was a prophetic authority in Neurosciences, who like the Pre-Socratic philosophers was characterized by a right and acute foresight in Neurology, having also the capacity to harmonize the precious deep knowledge of the Clinical Neurology with the rapid flow of the new data of the clinical and experimental investigation. Franz Gerstenbrand was also inspired by the Hippocratic medical philosophy, insight, ethics and aphorisms, which harmoniously amalgamated with the current scientific doctrines, proclaiming them all over the medical world with inexhaustible enthusiasm.

Franz Gerstenbrand, was born on $6^{\text {th }}$ of September 1924 in Northern Moravia (Nordmähren). His birthplace was sanctified by the mission of the brothers Saint Cyril and Methodius, the Thessalonian intellectual missionaries, who went in the Great Moravia in $862 \mathrm{AD}$, for evangelizing the Slavic people, devising also Cyrillic alphabet.

Franz Gerstenbrand graduated from Vienna University, "Cum Laude", in 1950, and immediately, he started postgraduate training in Neurology and Psychiatry at the same University, under the directorship of Prof. Hans Hoff. In 1976, he was elected Professor of Neurology and appointed head of the University Department of Neurology at Innsbruck University, where he stayed til his retirement in 1994. Under his directorship the department of Neurology became one of the best organized and functioned university departments in Europe.

Franz as Professor Emeritus demonstrated a unique continuous enthusiastic activity in the international field of Neurological sciences, being plenty of visions, perspectives and hope for an international collaboration for the progress of Neurology, the excellency of neurological education and the amelioration of the quality of life of the neurological patient. Among the numerous awards and honorable distinctions that Franz Gerstenbrand have received for his very eminent scientific, intellectual and humanitarian contributions are his Honorary Doctorate of the Charles University in Prague, in June 1997 and his Honorary Doctorate of the Medical School of Aristotelian University of Thessaloniki, on $27^{\text {th }}$ of June 2003.

Franz was also the recipient of the Silver Medal for Achievements for the Republic of Austria, of the Honorary Cross for Science and Arts of the Austrian Republic, of the Valeriy-Gagarin-Medal of the Russian Space Organization, of the Honorary Medals of the Country of Tyrol and the Medical University of Innsbruck, of the award of the Southern Moravia for the Culture. In 2014, Franz was awarded the

\author{
Stavros J Baloyannis \\ Research Institute for Alzheimer?s disease, Aristotelian \\ University, Greece
}

Correspondence: Stavros J Baloyannis, MD, PhD, Professor Emeritus, Aristotelia Univesity, Angelaki 5, Thessaloniki 5462I, Greece, Tel 302310270434, Fax +302310434; Email sibh844@otenet.gr

Received: October 03, 2017 | Published: October 28, 2017

Gold Medal of the city of Graz. He was also the recipient of Lifetime Achievement Award by the WFN.

Franz Gerstenbrand was elected Honorary Member of the European Academy of Neurology. In addition, he was elected honorary member of the Senate (Senatus) of the University of Krems in June 2003. In November 2001, Franz was elected honorary president of the Austrian Society for Parkinson's disease, honorary president of the Austrian Neurological and Psychiatric Society, honorary president of the Russian neurological Society, honorary president of the Polish medical Society, of the Czech Neurological Society, of the Hungarian Neurological Society of the Austro-Myanmar scientific society, he elected also honorary president of the medical Society «J.E. Purkynje». Franz was also member of American Academy of Neurology and member of the Royal Society of Medicine of the UK as well as of many other Austrian and international scientific societies.

Franz Gerstenbrand's main noble ambitious vision was the unification of the European Neurology. He was endeavoring to increase a peaceful, friendly, respectful and sincere collaboration among the European neurologists, indiscriminately to their political, ideological, philosophical background, based mainly on the scientific enthusiasm, the medical ethics and their beneficial contribution for the amelioration of the quality of life of the neurological patient.

In 1962, Franz founded the Danube International Neurological Group, which later became a Society and started organizing annual symposia (Danube Symposia) with the participation of neuroscientists coming from western and eastern countries of the Danube region. In promoting a close collaboration of all the European countries in the field of Neurosciences, In, Franz Gerstenbrand, founded in Prague in 1989, the Pan European Society of Neurology, which was evolved to be the European Federation of Neurological societies (EFNS). EFNS linked harmoniously the Neurologist of Europe by annual congresses 
and scientific awards, inspiring them the principle of gentle and productive collaboration on the basis of equality, friendship, dignity and respect.

EFNS was later a strong background for the foundation of the European Academy of Neurology (EAN) in 2014, which unified all the European Neurological Societies in a common Forum.

In addition Franz succeeded in creating a Scientific Society for Neurorehabilitation in Austria and abroad, resulting in the foundation of World Federation of Neurorehabilitation (WFNR) in Venice in 2003. WFNR established in 1013 "Gerstenbrand's award", in recognition of Franz' continuing contribution to neurorehabilitation.

Franz Gerstenbrand collaborated constantly with the Hellenic Society for the amelioration of the quality of life of chronic neurological patients, which was founded in Thessaloniki, in 2000. Franz Gerstenbrand was the honorary president of the ten international congresses, which were organized by the society and were held in Constantinople, Vienna, Alexandria, Odessa, Catania, Marseille, Thessaloniki, Delphi and Athens.

Franz' continuously increasing efforts for a serious and responsible education in Neurology and Neurosciences were accomplished by the foundation of the Neurological Academy for Young Neurologists in Southern Moravia, which during the summer months, were offering high professional knowledge on Neurosciences by eminent professors who released lectures, organized seminars and group discussions to large number of young neurologists.

Franz Gerstenbrand's intellectual horizons were extended far beyond Neurosciences including philosophy, religion, politics, history, archeology, music, painting, eastern philosophy and culture, African studies and linguistics. He studied extensively Greek philosophy, he delved deeply in Aristotle and Stoics, he admired the classic Greek literature and art, the lyric poets, the ancient drama, the Greek science, and he studied profoundly the scrolls of the Hippocratic collection and the treatises of Galen. He respected, preserved and practiced the Academic and Medical ethics constantly to the end of his life.

His gentle ideal to unify neurologist in a friendship, peaceful and cordial collaboration for the advancement of Neurosciences reached far beyond Europe, to North and South America, to Asia and Africa. He devoted much valuable time in Myanmar, organizing neurological departments in Universities, releasing lectures, supervising post doctoral researchers, transfusing continuously his wisdom, his illimitable experience and his high moral values to young neurologists. He was gratefully honored and awarded by the Republic of the Union of Myanmar and he was elected President of the Austrian Myanmar Society.
In addition, Franz introduced and organized many important programs for educational and technological support to African countries, elevating the neurological services and inspiring the wish for further erudition in Neurosciences.

Franz Gerstenbrand, as author gained a unique international recognition. He published 780 papers and 12 Textbooks and Monographs. To 1967 Franz described the traumatic apallic syndrome, in his habilitation treatise, which was published as monograph by Springer-Verlag, Wien entitled "Das traumatische apallische Syndrom, Klinik, Morphologie, Pathophysiologie und Behandlung". This memorable treatise, which was the first important contribution in the pathophysiological and clinical analysis of vegetative state, made him very well known in Europe and America.

In addition his contribution in the treatment of Parkinson's disease was also of substantial importance, since he was among the first neurologists, after George Kozias, who introduced levodopa therapy in Parkinsonian patients. In parallel, Franz studied and analyzed extensively the premorbid personality of Parkinsonian patients, including cases of personalities, who played a very crucial role in History, Politics and Church.

Franz harmonized perfectly the theory with the practice. By his high intelligence and immense experience Franz could find the right and most applicable solution in many complicated and thorny problems, being also able to foresee many scientific developments and to predict with prophetic accuracy the mission of neurosciences in the global society.

Franz' personality was adorned with magnanimity, exceptional kindness, gentleness, politeness, inner harmony, prudence. He was characterized by profound respect to human dignity, devotion to righteous principles and genuine love and compassion to the patients.

For all those reasons, Franz was the invaluable mentor of many neurologists and researchers and the pure scientific and moral physician's prototype for young neurologists in Europe.

For Franz Gerstenbrand the following Heraclitus' axiom has an evident validity.

\section{Acknowledgments}

None.

\section{Conflicts of interest}

None.

\section{Funding}

None. 